\title{
Creativity in Online Music Education Methods Courses: A Narrative Autoethnography
}

\author{
Heather Waters \\ Adelphi University, United States
}

\begin{abstract}
During the COVID-19 pandemic, the author, a music teacher educator, quickly adapted instruction to be fully online for courses that were previously taught in person. The author sought to continue to prioritize creative musical expression, now in online class spaces. This autoethnographic narrative inquiry highlights the author's perceptions of challenges and successes facilitating creativity with preservice music educators in their online music education methods courses.
\end{abstract}

\section{Introduction}

The COVID-19 pandemic created an unprecedented shift in teaching and learning, and has exacerbated existing issues of inequality and educational access. Since March of 2020, music educators in the United States have become quite familiar with challenges inherent in online and restricted in-person instruction, including technology issues (such as latency and lack of access), and safety protocols that prohibit singing, sharing of instruments, or close social interaction. Most music education methods courses prioritize active, embodied participation with high levels of in-person interaction. Prior to the COVID-19 pandemic, the author taught all music education methods courses entirely inperson. These courses included Elementary Music Education Methods, Classroom Instruments, Diverse School Settings, and Secondary Music Education Methods. These courses heavily utilized interactive in-person musical activities including singing, playing instruments, and creative movement. All of the courses included a strong emphasis on developing teaching skills for the future music teachers within the context of active, socially-situated music making.

In March of 2020, many of these class activities became unsafe during the COVID-19 pandemic, and the author, along with most music teachers and music teacher educators, had to drastically adapt instruction midway through the spring 2020 semester. Because these courses were not originally designed as online courses, suddenly shifting these courses to fully online instruction presented challenges, including student access and accountability, and a lack of direct social interaction and engagement. During this shift, the author sought to continue to emphasize creative musical expression and holistic student well-being, and embraced the challenge of adapting instruction to ensure creative musical expression was still prioritized in these courses.

As part of this inquiry, the author assumed that her identity as a researcher, teacher, and musician are intersecting parts of a whole. Each segment of her professional identity had, and continues to have, significant overlap, as well as features that are distinct to each part. As a researcher, teacher, and musician, she is continually seeking to integrate her research with her teaching practice and musicianship. As a music teacher educator, she also seeks to model this flexible, integrated approach for her university students, and encourage them to embrace inquiry as a natural part of being a reflective practitioner. She views engagement in self-study as a valuable form of inquiry that can inform and improve teaching practices.

\section{Literature Review}

Limited research exists related to teaching music during the COVID-19 pandemic. This is of course because the pandemic is still ongoing and researchers have not had adequate time to disseminate their findings. Likely, there will be a plethora of research that emerges following the pandemic, but currently research on this topic is limited, and this study will contribute to this gap in the literature.

Even in the absence of abundant research related to teaching during the COVID-19 pandemic, it can be inferred that many of the teaching challenges that existed pre-pandemic continue to persist, and in some cases have been magnified. Prior to the pandemic, many educators were already familiar with disparities related to educational access and resources [1], but preliminary evidence suggests this has been exacerbated during the pandemic [2], [3], [4]. These inequalities potentially contribute to greater variance in student's holistic needs, with some students having access to abundant resources, and others lacking basic 
necessities for successful learning. During in-person instruction on a university campus, some of these disparities could previously be mediated because the students had access to the same resources in shared physical classroom spaces. However, once instruction shifted to fully online classroom spaces, differences in access and home environments became a greater concern. Although addressing access issues is not the primary focus of this study, the author recognized that these issues pervaded all aspects of instruction, student participation, student engagement, assessment, and evaluation. The author sought to mediate the effects of these inequalities by fostering creativity and individual expression, and recognized that high-quality student-teacher interactions are one of the primary factors that facilitate student engagement and meaningful learning [5], [6].

From the limited research on music teaching during COVID, one study of instrumental music educators [6] highlighted the importance of prioritizing connectedness and collaboration between students and teachers. Utilizing teaching approaches that fostered relationships, empathy, connection, and reinforced connectedness to others via musical experiences were beneficial to students and teachers alike. Although a detailed review of literature related to relationship-based, holistic, social-emotional learning is beyond the scope of this paper, the author approached her teaching with these considerations in mind, and sought to facilitate student growth, specifically related to musical and pedagogical creativity, via a focus on students' holistic well-being, rather than a strict focus on musical concepts and skills.

\section{Purpose and Research Questions}

The purpose of this self-study was to examine the experiences of a music teacher educator exploring ways to facilitate creativity in online undergraduate music education classes during the COVID-19 pandemic. Via this self-study, the researcher/author sought to educe [7] herself regarding her own assumptions and teaching processes, in an effort to produce more meaningful opportunities for her undergraduate students to actively engage in creative musical expression in online courses.

The guiding questions for this inquiry included:

(1) What challenges emerged in facilitating creativity in online music education classes?

(2) How can inclusive instructional practices be utilized to support all musical learners in all contexts (whether in-person, hybrid, and online)?
(3) What successes have there been in shifting music education methods courses online?

(4) What additional possibilities can be uncovered that promote musical creativity in all learning modalities?

(5) How does educing teaching practice (relative to online music education methods courses) offer insights that resonate with other music teacher educators?

\section{Methodology}

This narrative autoethnography represents an exploration of creative musical expression as shaped via relational and environmental factors during the COVID-19 pandemic. The author interrogated and situated her own conceptualizations of possibilities and limitations inherent in teaching music education courses online. She connected her teaching experiences to conceptions of spatialities [8, 9, 10] and how these relate to place and space-based learning in online environments.

Data sources for this study include written and audio journal reflections, teaching artifacts and recordings, and informal notes. As part of the research process, autoethnographic narratives were restored for the "essence of being and the source of knowing" [11] and are presented as interim texts [12]. This article highlights short excerpts of these narratives collected between March 2020 and May 2021. This inquiry will potentially continue as long as the author's teaching remains primarily online, with additional narratives added over time.

\section{Potential Implications}

Potential implications for this study include formulating strategies for facilitating inclusive teaching praxis within online, hybrid, and other modified learning environments, and potential adaptations to teaching music education methods courses online that still continue to promote active, creative musical expression. As a narrative autoethnography, the findings or implications are not generalizable, but readers are invited to reflect on the examples in ways that resonate with their own teaching practice.

\section{Narratives}

In narrative autoethnography, the product of the inquiry is context-specific excerpts from autobiographical narratives that have been re-storied multiple times. Restory refers to revisiting the narratives multiple times and viewing them through shifting lenses as perspectives change. The following 
are short excerpts from the complete autobiographical narratives that highlight the experience of facilitating creative musical expression online. Ideally, the goal of these narratives is not to craft neatly packaged themes or generalizable implications, but to display layers of consciousness, and connect the author's personal experiences to the broader experience of continuing to facilitate musical creativity in online music education methods courses [13]. The narratives are shared in first person language, to highlight the personal experiences of the author.

This first narrative excerpt was written in spring of 2020, as the author and her students struggled to adapt to the very real losses they were experiencing, both in terms of actual human life and in terms of the loss of their learning communities as they knew them.

This is so surreal. Almost apocalyptic. The woman from the psychology department who used to sit next to me in the academic affairs committee meetings has died. Our 90-year-old neighbor's wife just died in the care facility she lived in. Someone else two houses down was just carted away by emergency medical technicians in full hazardous materials gear. I do not know how I am supposed to focus on immediately adapting to online teaching in the midst of this. What about the bigger life and death concerns we are dealing with right now?

How am I supposed to teach students how to be teachers when they are genuinely concerned for their own lives and the lives of their families? Concerns about shifting to online instruction seem trivial compared to these fears, but this is our reality. We will have to find a way to continue. I am charged with teaching students how to be music teachers in the midst of this global catastrophe and I will find a way to do so.

The physical loss of life is very real, but beyond that, our learning community also feels like it has been destroyed. Just last week we were singing together, dancing together, and laughing freely. Before, in our classroom spaces we were interacting in creative and engaging ways. Now we view each other only through a screen.

We can also no longer interact with children in schools. How am I supposed to teach these students to be teachers when they can't have actual experiences with children? They're prohibited from participating in many schools, even online, due to concerns over privacy. So what are we going to do?

The next narrative was written in May 2020, after two months of adapting to the pandemic restrictions.

We are all still creative people. This hasn't changed. There's a balancing that's occurring with every interaction in which we're navigating how best to shift our sense of creative expression within this kind of forced autonomy online. Things as simple as dancing a folkdance, sharing mallets on the xylophones, or singing in harmony together are all gone, but we've begun to uncover other possibilities. In essence, this time of extreme stress and challenge is forcing us to examine ways we can still be creative. There is of course the stereotype of the tormented artist, and although I don't think that kind of torture is always necessary for your art, so to speak, I'm noticing that difficulties, restrictions, and working within limits can also spark creativity.

I'm thinking of how we facilitate musical improvisation with children. Often, if there are too many possibilities such as too many instruments to try or too many ways to express ourselves, the choices can be overwhelming and stifling in their own way. Sometimes working within limited possibilities and adapting to constraints can produce creativity and great beauty. We've pivoted and adapted as best we can. I've shifted, and the students have shifted in so many ways. But what have we done specifically? What has changed?

The final narrative excerpt was written in December 2020, after almost 9 months of living under COVID19 restrictions.

We've learned how to share videos of our music teaching with each other online, even if it means teaching to a row of toys in our house, or teaching a willing member of the household even if they are not even close to the target age range for the lesson. Younger siblings and parents have filled in as designated first graders or fifth graders, and we've demonstrated in very clear ways how flexible we are in adapting our instruction to meet learners' needs.

We've learned to interact via breakout rooms in small groups, and substitute our dancing together for dancing alone in our own personal space. We've learned to record different parts of a musical piece using different apps and recording technology that is brand new to us, in order to hear all the parts and still try and create musical harmony in our online space. Sometimes this works well, and other times there are struggles, but we are all learning alongside each other and celebrate our successes.

Since we don't have access in our homes to all the instruments we normally do on campus, we've learned to substitute pencils for rhythm sticks, or pots and pans for drums, and use whatever we have. This will come in handy if any of us teach in a classroom in the future that has few resources. We've recognized that we can do all our rhythm lessons using nothing but our own bodies. Our spaces have changed, but we 
draw on our own creativity and use it to seek out the best ways to creatively express our creativity! Some types of interaction are gone, but we've adjusted as best we can, and other modes of creative expression have emerged. Some students compose using loops or other composition apps, and others have embraced audio and video recording technology to assist them in their creative projects.

Most of all, we've learned to support each other and continue to believe that our strength is in our community, and our creative community still exists, even if our interactions are in slightly different forms online. We are still creative and engaging music teachers, and we will continue to grow in the midst of limits, and hone our skills at adapting our instruction to whatever challenges we face.

\section{Discussion}

It may seem abrupt to not package the narratives into more precise themes, but formal implications and recommendations are usually avoided in narrative inquiry, as this would artificially compact something that is open-ended "research as art" into a form that is too fixed. The intent of sharing these narratives is to foster thoughtful long-term, personal reflection that contributes to expanded self-awareness, to make personal applications to teaching praxis, and to reflect on the ways the narratives resonate with personal experiences.

The author asserts that participating in reflective narrative inquiry has fostered an expanded selfawareness, and has had a positive impact on personal and teaching growth. These reflective narratives will continue to be added to over time to enhance teaching practices, and creativity will still be facilitated, even in the midst of challenging circumstances such as suddenly pivoting to fully online instruction in music education methods courses.

\section{Conclusion}

Although these narratives are not generalizable, readers are invited to reflect on ways they resonate with their own experiences teaching in online contexts. This study represents one teacher educator's experiences shifting in-person music education methods classes online during the COVID-19 pandemic. This study contributes to the literature that will likely emerge related to music teaching during the pandemic, and connects to ways that teachers can support students' creative musical expression by prioritizing connectedness, community, and engagement. By engaging in heightened selfreflection as part of this inquiry, the author experienced an increased comfortability and responsiveness in adapting in-person classes to an online format. Perhaps other educators will experience similar benefits if they choose to engage in reflective, personal inquiry related to their own teaching practices in online courses.

\section{References}

[1] Palmer, E. S. "Literature Review of Social Justice in Music Education: Acknowledging Oppression and Privilege. Update: Applications of Research in Music Education, 36(2), 2018, pp. 22-31.

[2] Andrew, A., Catta, S., Costas-Dias, M., Farquharson, C., Kraftman, L., and Krutikova, S. Learning During the Lockdown: Real-time Data on Children's Experiences During Home Learning. IFS Briefing Note BN288. London: Institute for Fiscal Studies, 2020.

[3] Bol, T. Inequality in Homeschooling During the Corona Crisis in the Netherlands. First Results from the LISS Panel. Working Paper, University of Amsterdam, 2020.

[4] Daubney, A., and Fautley, M. "Editorial Research: Music Education in a Time of Pandemic," British Journal of Music Education, 37(2), 2020, pp. 107-114.

[5] Niemiec, C. P., and Ryan, R. M. (2009). "Autonomy, competence, and relatedness in the classroom: applying self-determination theory to educational practice," Theory Res. Educ. 7, 133-144. doi: 10.1177/1477878509104318.

[6] deBruin, L. R., "Instrumental Music Educators in a COVID Landscape: A Reassertion of Relationality and Connection in Teaching Practice," Frontiers in Psychology, 11, 2021, doi: 10.3389/fpsyg.2020.624717.

[7] Nachmanovtch, S. Free Play: Improvisation in Life and Art, Penguin Putnam, New York, 1990.

[8] Crampton, J., and Elden, S. Space, Knowledge, and Power: Foucault and Geography, Ashgate, England, 2007.

[9] Foucault, M. Power/knowledge: Selected Interviews and Other Writings, 1972-1977, Pantheon Books, New York, 1980.

[10] Smith, K. "Producing Governable Subjects: Images of Childhood Old and New," Childhood: A Global Journal of Child Research, 19(1), 2012, pp. 24-37.

[11] Barrett, M. S., and Stauffer, S. L. (2012). Narrative Soundings: An Anthology of Narrative Inquiry in Music Education, Springer, New York, 2012.

[12] Clandinin, D. J., and Connelly, F. M. Narrative Inquiry: Experience and Story in Qualitative Research. Jossey-Bass Publishers, San Francisco, 2000.

[13] Ellis, C., Adams, T. E., and Bochner, A. P. "Autoethnography: An Overview," Forum: Qualitative Social Research, 12, 2011. 